\title{
Simulating the Inter-Building Effect on Energy Consumption from Embedding Phase Change Materials in Building Envelopes
}

Yilong Han ${ }^{\mathrm{a}}$, John E. Taylor ${ }^{\mathrm{b}, *}$

a Charles E. Via, Jr. Department of Civil and Environmental Engineering , Virginia Tech, 315 Patton Hall, Blacksburg, VA 24061, USA

${ }^{\mathrm{b}}$ Charles E. Via, Jr. Department of Civil and Environmental Engineering , Virginia Tech, 114 Patton Hall, Blacksburg, VA 24061, USA

\begin{abstract}
The built environment contributes significantly to rapidly growing world energy consumption. Along with urbanization, buildings continue to escalate this trend owing to their tighter spatial interrelationships and the influence of their surrounding micro-environment. The concept of the Inter-Building Effect (IBE) was introduced to understand complex mutual impacts within spatially-proximal buildings. Recent research has revealed that inter-building reflection or shading can have nuanced effects on a month by month basis depending on the climatological context. The application of phase change materials (PCMs) has begun to be examined by researchers due to its ability to store and release heat within a certain temperature range. In this paper, we sought to explore and understand if PCM embedded building envelopes could potentially mitigate negative thermal-energy impacts within spatially proximal buildings. Building upon previous IBE research and simulation models, we conducted several building network simulations with different PCM settings in different climatological contexts. The results showed considerable improvements (up to 17\%) of annual HVAC energy consumption when PCM-embedded building envelopes were used in the control building. The findings expand and deepen our understanding of the IBE, and may help minimize negative mutual influences across buildings that lead to increases in energy consumption in urban environments.
\end{abstract}

Keywords: Building Networks; Energy Efficiency; Inter-Building Effect; Phase Change Material; Simulation

\footnotetext{
* Corresponding author. Tel.: +1 540231 0972; Fax: +1 5402317532.

E-mail addresses: ylhan@,vt.edu (Yilong Han), jet@vt.edu (John E. Taylor)
} 


\section{Introduction}

Energy and its impact on the environment has become a central issue facing society. According to the latest energy data statistics from the International Energy Agency [1], annual global energy consumption has grown from 4000Mtoe (million tonnes of oil equivalent) in 1971 to nearly 9000Mtoe in 2011. Over the last 40 years, carbon dioxide emissions have doubled [1]. The rapidly growing world energy expenditure not only causes supply difficulties and depletion of fossil energy resources, but also significantly influences the human living environment by triggering climate deterioration locally (e.g. Urban Heat Island (UHI) effects) and worldwide (e.g. global warming).

The mean global temperature has increased by 0.6 degree Celsius during the 20th century [2]. However, a worldwide increase of as much as 5.8 degrees Celsius is expected to occur by the end of the 21st century [3]. Urban areas are the major source of carbon dioxide emissions contributing to greenhouse gases that increase global climate and environmental change. Warming has been found at more significant

levels over the land than over the ocean, and more intense in the northern hemisphere where 90 percent of people live [3]. Referred to as a significantly warmer metropolitan area than its surrounding rural areas, the heat effects by the UHI add discomfort to urban residents and increase the air-conditioning load substantially, especially in summer $[4,5]$. Warmer cities have been frequently associated with global warming although they may not necessarily have a direct relationship [2]. The intensity of UHI could result from a function of urban morphology, urban building physical characteristics, waste heat release, as well as, regional climate factors [6]. However, it is also the result of the dense construction surfaces that absorb solar radiation more than natural surfaces, and the anthropic heat flex due to the cooling and heating of buildings [4].

Buildings and the built environment are major contributors to the trends of both the rising energy consumption and deteriorating urban micro-environment. $32 \%$ of total final energy consumption and nearly $40 \%$ of primary energy consumption are attributed to buildings on the planet [7]. In the United States, nearly half $(47.5 \%)$ of all energy produced and three quarters of electricity is consumed by the 
building sector every year [8]. The ongoing and emerging industrial developments and urbanization in fast developing countries and underdeveloped regions will also intensify energy usage and cause supply difficulties [9]. According to a recent report by the United Nations, population in urban areas is projected to increase by $72 \%$ from 3.6 million (2011) to 6.3 million (2050) in the next 40 years [10]. As a result, the energy and environmental issues attributable to urban buildings will become more challenging to the built environment itself and to society. Therefore, how to achieve a more sustainable built environment has become a grand challenge for engineers, building researchers, urban planners, and policy makers.

\section{Background and research objectives}

\subsection{Tighter and more complex urban inter-building relationships impacting energy use}

In the presence of rapid urbanization, the relationship between building density and urban form has attracted wide interest, as it is expected that tighter and more complex building geometries will be more prevalent in urban areas in the following decades. Urban morphology, characterized by building density, size, height, orientation, and layout, could cause considerable variations in the local environment and microclimates. Mathematical and geometrical analyses have been conducted to study the issue concerning building height, plot ratio, orientation, solar obstruction, etc., and early research generated insightful discoveries that urban microclimates and buildings are inextricably interwoven [11-13]. It is difficult to predict one building's energy performance accurately without considering the close proximity of other buildings and the energy implication that could result.

To understand the complex interactions that cause urban thermal-energy dynamics within spatially proximal building networks, the concept of the Inter-Building Effect (IBE) has been introduced and further investigated over the last several years [14-16]. Research has demonstrated that the interrelationship between buildings within building networks results in substantial inaccuracies (up to $42 \%$ in summer, and up to $22 \%$ in winter) of energy consumption predictions for space heating, space cooling, and lighting $[14,15]$. The research also demonstrates that, irrespective of the climatological context, the 
energy performance of one building can be meaningfully impacted by surrounding buildings through mutual reflection and mutual shading, the two primary components that make up the IBE.

In order to better understand and explore successful urban planning and building designs that could affect the IBE, researchers disaggregated and quantified the shading effect and reflection effect separately from the IBE [17]. The more nuanced analysis found shading to contribute to increased heating loads while reflection increased cooling energy required for spatially-proximal buildings. The monthly analysis of several weather profiles of multiple U.S. metropolitan cities under different climate zones revealed that the contribution of reflection and shading varies on a month-to-month basis as the impact of IBE is closely related to geographical location and climatic conditions. However, limited research has sought solutions to mitigate negative thermal energy inter-building relationships. Building energy performance in tropical cities with longer summers, longer daylight time and higher demand for cooling energy would benefit from mitigated reflection effect all year round. Therefore, directional reflective building envelopes have been investigated to help lessen mutually reflected solar radiation and mitigate Urban Heat Island effects within urban canyons in warmer areas [16]. General solutions to address such negative effects within building networks are still largely unrealized, especially for the temperate areas where shading and reflection impact IBE differently depending on the season, or even over the course of a day.

\subsection{The potential of thermal storage techniques within building networks}

Energy consumption can be reduced by improving the thermal performance of the enclosures. Increasing the building envelope thermal resistance had been implemented as a common practice, but is subject to limitations of wall thickness and high costs. Improving thermal storage capacity was later introduced as an alternate solution. With the important characteristic to store and release heat within a certain temperature range, the use of phase change materials (PCMs) can significantly shorten overheated hours and shift peak electricity loads $[18,19]$. As a result, PCMs could work as a suitable and promising 
solution for not only increasing indoor thermal comfort but also reducing the energy consumption of buildings.

Conventional building materials usually have sensible heat storage effects such that the heat is stored or released accompanied with temperature changes in the storage media. In contrast, PCMs have greater heat storage capacities with latent heat storage, where the heat is stored or released as heat of fusion/solidification during the phase change process of the storage with a small variation of PCM volume. They can be divided into different subcategories based on their chemical composition, such as organic compounds, inorganic compounds and eutectics [19]. Each material has its typical range of melting temperature and its range of melting enthalpy which could be employed for the thermal comfort context. PCMs have attracted attention by building researchers in the recent past, and several recent papers [19-22] reviewed the state-of-the-art on knowledge of PCMs today specifically for building applications including PCM selection, PCM thermal stability, impregnation of PCMs into construction materials (such as wallboards, walls, floors and ceilings), and evaluation and calibration for PCM numerical simulation. In the building application, the PCMs with phase change temperature 18 to 30 degree Celsius are preferred to meet the need of thermal comfort of building occupants [19]. Previous exploration demonstrated that PCMs have different benefits depending on quantity, types, locations, and climates. Despite the various advantages of the PCM application in buildings, the commercial implication of PCMs is yet to be fully explored. This is owing to the fact that most available information is limited to miniature models or prototype laboratory tests [20]. The gap between current PCM research and practical applications has also been identified due to a lack of realistic case studies and research [20]. Moreover, nearly all of the previous studies are discussed within the context of stand-alone buildings.

In this paper, we seek to evaluate the application of PCMs from the perspective of inter-building relationships that extend beyond a stand-alone building scenario and to explore the impact of PCM technology in a dense urban building environment. By implementing advanced numerical analysis approaches, this research aims to fill the literature gap by examining whether PCM-embedded building 
envelopes could serve as a possible solution to mitigate the negative thermal-energy impact of IBE through parametric analysis.

\section{Methodology}

To understand and quantify the impact of PCMs to inter-building thermal-energy performance, we conducted our research using the following methodology. Building upon early research on PCMs application for stand-alone buildings, we firstly develop several hypotheses using inter-building effect modeling techniques to examine building network scenarios. We then introduce how we design and model different simulation sets in the dynamic simulation environment. Parametric analyses were conducted to further investigate and evaluate PCM-embedded envelopes by comparing PCM locations in building envelopes, PCM types, and climatological conditions.

\subsection{Hypotheses development and research initiatives}

PCM technology has been studied in building applications in many different ways with resulting positive effects on thermal comfort and energy implications $[19,22]$. Therefore, we propose Hypothesis 1 in the inter-building context.

Hypothesis 1. PCM-embedded building envelopes lead to reductions in cooling and heating energy in an urban context where buildings are in close proximity.

Location of PCM layers is critical for wall performance in terms of controlling heat transfer capabilities [23, 24]. Through a dynamic wall simulator, PCM layers at varying distances from the interior gypsum layer have been studied experimentally through differential scanning calorimeter tests and cooling experiments [24]. The results showed that the most optimal location for PCM layers should be within the first insulation layer [24]. With that, we propose Hypothesis 1a to further verify Hypothesis 1 in the simulated inter-building environment. 
Hypothesis 1a. PCM-embedded building envelopes lead to higher reductions in cooling and heating energy when the PCMs are embedded in the inner layers in an urban context where buildings are in close proximity.

PCM technology has been suggested to be more efficient when applied to roof areas for single buildings [19]. In the inter-building scenario, mutual reflection and mutual shading of neighboring buildings could cause significant thermal-energy impact $[14,17]$. Thus, vertical building envelopes (i.e. exterior walls) can also play an important role on energy saving by creating an enclosed PCM space. Therefore, we propose Hypothesis 2.

Hypothesis 2. Both PCM-embedded roofs and PCM-embedded building walls have positive influences on energy savings in an urban context where buildings are in close proximity.

In addition, since different PCMs have their own material properties and temperature-enthalpy profiles, the effectiveness of PCMs are largely dependent on melting temperature ranges and local weather conditions. A number of PCM types and climatological data are used in this numerical analysis for a more comprehensive study.

\subsection{Simulating the IBE in a dynamic environment}

Over the last several decades, dynamic building simulation has developed rapidly by building researchers for front-end design and a more sustainable building lifecycle. Simulation tools offer powerful functionalities and best practices to predict and improve building energy performance. EnergyPlus [25, 26], an energy analysis and thermal load simulation engine developed and distributed by U.S. Department of Energy, has become a popular building energy performance simulation tool owing to its sophisticated and validated functions. It was also utilized for previous IBE research for dynamic building analyses.

Early IBE simulation efforts were conducted based on a realistic physical urban block in the state of New York to study energy consumption of space cooling and space heating [14]. Later, IBE research was expanded to investigate the energy discrepancies in lighting and validated the IBE, e.g., mutual shading and mutual reflection, as an important effect to be modeled in situations where buildings are 
surrounded by other nearby buildings [15]. Real-world experimental work and empirical data were used to calibrate and verify the simulation work. An essential geometric element for shading and reflection in the EnergyPlus environment, the shading surface, was used extensively to achieve modeling objectives while avoiding excessive running times.

In this study, we modeled a nine-building block as a hypothetical building network as illustrated in Figure 1. The reference building is modeled as a three-story office building in the center of the building network with eight shading-surface buildings surround it. The morphology of each building within the building network is identical with a square shape of 10 meters per side. The distance between buildings was set to be 5.25 meters (Height/Width ratio=2) for both the East-West direction and the North-South direction. This baseline non-PCM building and modeling information (construction materials, temperature set-points, schedules for lighting, equipment, and occupants, etc.) were inherited from previously published IBE research [14-17] for the credibility of the numerical analysis. Some key parameters are listed as below. The opaque envelope of the reference building consists of four layers, external brickwork $(0.10 \mathrm{~m})$, XPS extruded polystyrene $(0.080 \mathrm{~m})$, light weight concrete block $(0.010 \mathrm{~m})$, and internal gypsum plasterboard $(0.013 \mathrm{~m})$, with a global thermal transmittance of $0.314 \mathrm{~W} / \mathrm{m}^{2} \mathrm{k}$. The floor includes wooden flooring $(0.020 \mathrm{~m})$, mineral wool $(0.15 \mathrm{~m})$, floor structure $(0.20 \mathrm{~m})$, and external rendering $(0.025 \mathrm{~m})$, with a global thermal transmittance of $0.246 \mathrm{~W} / \mathrm{m}^{2} \mathrm{k}$. The roof also consists of four layers with asphalt $(0.010 \mathrm{~m})$, mineral wool $(0.15)$, air gap and roof structure $(0.20 \mathrm{~m})$, and plasterboard $0.015(\mathrm{~m})$, with a global thermal transmittance of $0.250 \mathrm{~W} / \mathrm{m}^{2} \mathrm{k}$. The external windows are modeled as double clear glass panes $(6 \mathrm{~mm}-6 \mathrm{~mm}$ with $6 \mathrm{~mm}$ air). The diffuse solar reflectance of the exterior building envelopes and the ground are set to be $40 \%$ and $20 \%$, respectively. The main working hour schedule is from 8 am to $6 \mathrm{pm}$ during weekdays. 


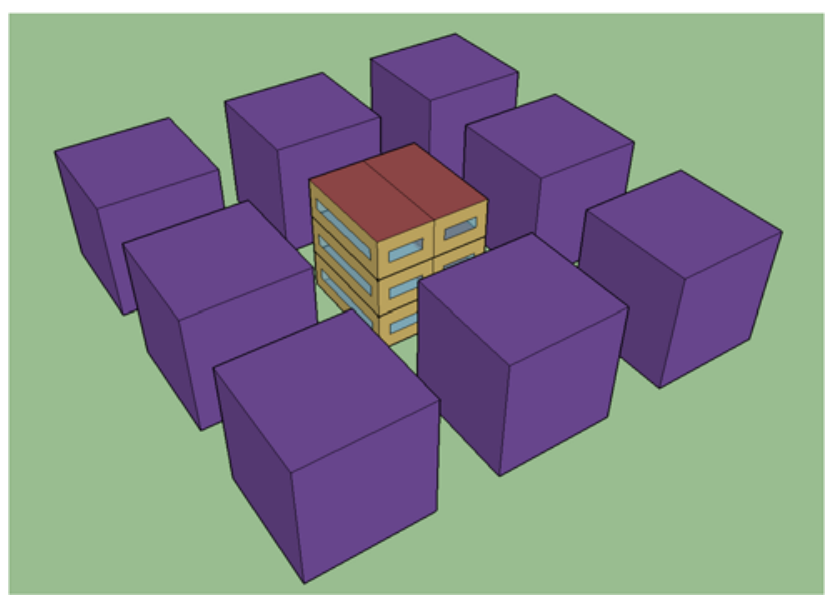

Fig. 1. Hypothetical nine-building network

\subsection{Simulating the impact PCM-embedded in the inter-building environment}

Using a one-dimensional conduction finite difference algorithm, the ability to simulation PCMs has been developed and studied in EnergyPlus. [27-29]. Particularly, Tabares-Velasco et al. [29] developed a procedure to verify and validate the PCM model using an approach as dictated by ASHRAE Standard 140, and also provided several suggestions addressing the limitations of current EnergyPlus PCM models. In this study, building models with PCM layers were built referring to published data and validated experimental parameters $[14,15]$. A typical microencapsulated PCM type is used for this analysis [29] and is indicated as PCM type "P22". It has a conductivity of $0.18 \mathrm{~W} / \mathrm{m}-\mathrm{k}$, density of 855 $\mathrm{kg} / \mathrm{m}^{3}$, specific heat of $2500 \mathrm{~J} / \mathrm{kg}-\mathrm{K}$, and a melting temperature point around 21.6 degrees Celsius. In addition to PCM type "P22", the simulation effort was carried out using five commercial BioPCM materials [28]. All BioPCMs have the same material properties of conductivity $(0.2 \mathrm{~W} / \mathrm{m}-\mathrm{k})$, density $(235$ $\left.\mathrm{kg} / \mathrm{m}^{3}\right)$, and specific heat $(1970 \mathrm{~J} / \mathrm{kg}-\mathrm{K})$, but different melting temperatures and temperature-enthalpy profiles. According to the melting temperature range from 21 to 29 degrees Celsius, the BioPCMs are indicated as “Q21”, “Q23”, “Q25”, “Q27”, and "Q29”, respectively. Different PCM layers were embedded within the volume of the building envelopes inherited from previously published IBE models. The thickness of PCM layers was set to 0.021 meter for all cases as one control parameter. The temperature-enthalpy profiles of all six tested PCMs are illustrated in Figure $2[28,29]$. The latent heat of 
individual PCM types was thus reflected. To avoid simulation errors, the time step of the simulation was set to three minutes as suggested by the program developers [25]. Monthly and annual simulation outputs were reported in the results.

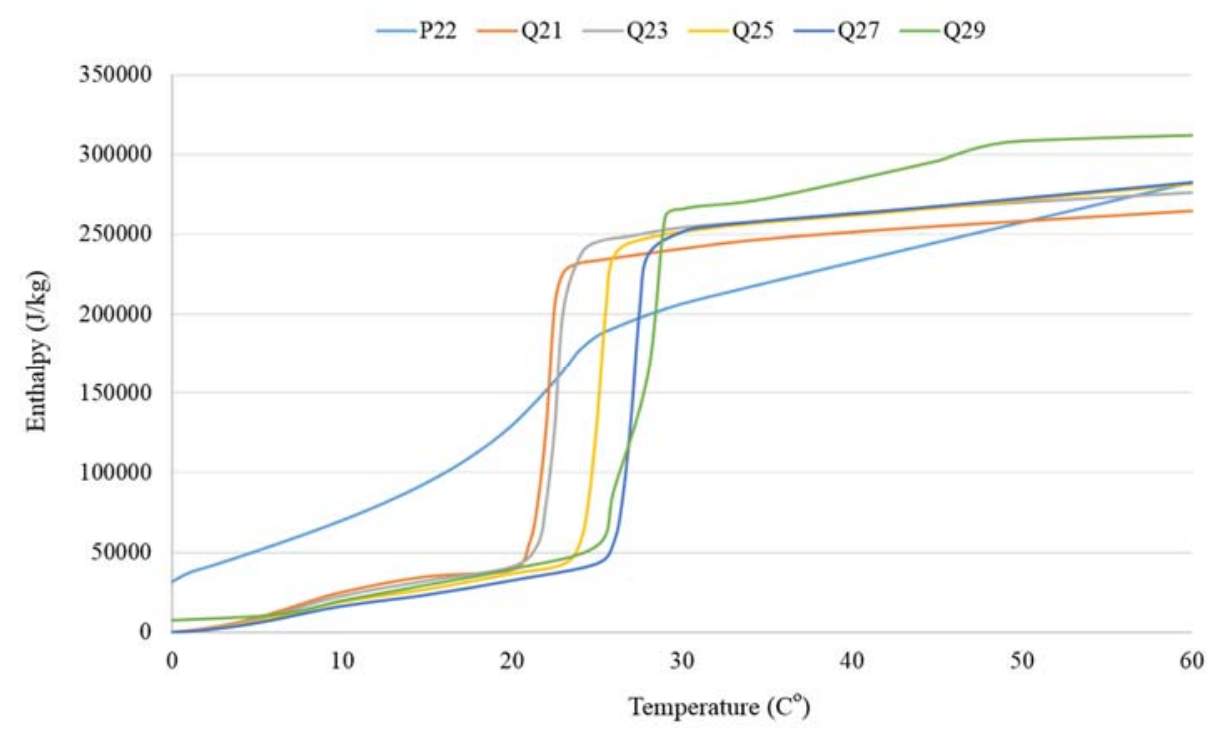

Fig. 2. Temperature-enthalpy profiles of six different PCM types [28, 29]

Previous IBE research has found that the impact of IBE vary by climatological context $[14,16]$. To investigate the impact of PCM building envelopes to the IBE, four typical U.S. cities from different climate zones-Washington, D.C., Minneapolis, MN, Los Angeles, CA and Miami, FL—were selected for this study. Minneapolis, MN and Miami, FL represent an extreme climate condition as the coldest and the hottest metropolitan city in the United States. Los Angeles, CA represents a subtropical Mediterranean climate while Washington, D.C. has a distinctive and roughly equal length seasons as a typical temperate city. Under the weather profile of each city, the impact of PCM was tested through a comparative study by setting the building envelopes of the control building as either conventional or PCM-embedded, by examining different locations of PCM layers, and by testing different types of PCMs. The energy performance of the reference building was monitored and reported over the course of the simulation period. 


\section{Analysis and Results}

\subsection{Case Study 1: The impact of PCM layer location within the volume of the walls on inter-building thermal-energy performance}

The first case study was designed to test the impact of PCM on IBE in general, as well as to test the effectiveness of PCM at varying locations within the volume of the building envelopes. A typical PCM type, "P22", is first used for this analysis. Annual results of control building energy consumption including space heating, space cooling, and total primary energy consumption are contained in Table 1, Table 2, Table 3, and Table 4 for Washington, D.C., Minneapolis, MN, Los Angeles, CA and Miami, FL, respectively. The left columns of these table indicate the simulation types: "NoPCM" stands for the pure IBE situation as baseline values; "PCM_OuterLayer" represents the results when the PCM layer is placed next to external brickwork; similarly, "PCM_MidLayer" and "PCM_InnerLayer" denotes the outcomes when the PCM layer is embedded in the middle layer of the envelope volume and closer to the internal plasterboard, respectively. In the rows of "PCM_OuterLayer", "PCM_MidLayer" and "PCM_InnerLayer", variation percentages were also calculated according to the baseline IBE values "NoPCM". A "+" is designated to indicate an increase in energy usage while a "--" means that saving would occur for that particular situation, indicating less energy is being used. For instance, the "-13.7\%" in Table 1 indicates a reduction of 13.7 percent for primary cooling energy consumption required for the reference building within the building network when the PCM layer is placed close to internal plasterboard.

Table 1

Reference building's energy consumption with different PCM layer locations within building envelopes in Washington, D.C.

\begin{tabular}{|c|c|c|c|c|c|c|}
\hline Simulation Type & \multicolumn{2}{|c|}{ Heating (kWh) } & \multicolumn{2}{|c|}{ Cooling (kWh) } & \multicolumn{2}{|c|}{ Total $(\mathrm{kWh})$} \\
\hline NoPCM & 18362.9 & & 7782.9 & & 26145.9 & \\
\hline PCM_OuterLayer & 18043.6 & $-1.7 \%$ & 7502.3 & $-3.6 \%$ & 25545.9 & $-2.3 \%$ \\
\hline PCM_MidLayer & 17719.5 & $-3.5 \%$ & 7168.7 & $-7.9 \%$ & 24888.2 & $-4.8 \%$ \\
\hline PCM_InnerLayer & 17596.3 & $-4.2 \%$ & 6716.2 & $-13.7 \%$ & 24312.5 & $-7.0 \%$ \\
\hline
\end{tabular}

\section{Table 2}


Reference building's energy consumption with different PCM layer locations within building envelopes in Minneapolis, MN

\begin{tabular}{|c|c|c|c|c|c|c|}
\hline Simulation Type & \multicolumn{2}{|c|}{ Heating (kWh) } & \multicolumn{2}{|c|}{ Cooling (kWh) } & \multicolumn{2}{|c|}{ Total $(\mathrm{kWh})$} \\
\hline NoPCM & 33959.6 & & 5787.3 & & 39746.9 & \\
\hline PCM OuterLayer & 33602.0 & $-1.1 \%$ & 5549.4 & $-4.1 \%$ & 39151.4 & $-1.5 \%$ \\
\hline PCM_MidLayer & 33283.0 & $-2.0 \%$ & 5299.2 & $-8.4 \%$ & 38582.3 & $-2.9 \%$ \\
\hline PCM_InnerLayer & 33217.1 & $-2.2 \%$ & 4941.1 & $-14.6 \%$ & 38158.3 & $-4.0 \%$ \\
\hline
\end{tabular}

Table 3

Reference building's energy consumption with different PCM layer locations within building envelopes in Los Angeles, CA

\begin{tabular}{lllcccc}
\hline Simulation Type & \multicolumn{2}{c}{ Heating $(\mathrm{kWh})$} & \multicolumn{2}{c}{ Cooling $(\mathrm{kWh})$} & \multicolumn{2}{c}{ Total $(\mathrm{kWh})$} \\
\hline NoPCM & 3078.9 & & 7321.5 & & 10400.4 & \\
PCM_OuterLayer & 2868.7 & $-6.8 \%$ & 6874.0 & $-6.1 \%$ & 9742.7 & $-6.3 \%$ \\
PCM_MidLayer & 2777.4 & $-9.8 \%$ & 6670.9 & $-8.9 \%$ & 9448.3 & $-9.2 \%$ \\
PCM_InnerLayer & 2655.9 & $-13.7 \%$ & 5978.6 & $-18.3 \%$ & 8634.5 & $-17.0 \%$ \\
\hline
\end{tabular}

Table 4

Reference building's energy consumption with different PCM layer locations within building envelopes in Miami, FL

\begin{tabular}{|c|c|c|c|c|c|c|}
\hline Simulation Type & \multicolumn{2}{|c|}{ Heating $(\mathrm{kWh})$} & \multicolumn{2}{|c|}{ Cooling (kWh) } & \multicolumn{2}{|c|}{ Total $(\mathrm{kWh})$} \\
\hline NoPCM & 377.0 & & 20062.6 & & 20439.6 & \\
\hline PCM_Outsider & 283.2 & $-24.9 \%$ & 19704.5 & $-1.8 \%$ & 19987.7 & $-2.2 \%$ \\
\hline PCM_Middler & 240.9 & $-36.1 \%$ & 19522.2 & $-2.7 \%$ & 19763.2 & $-3.3 \%$ \\
\hline PCM Insider & 192.7 & $-48.9 \%$ & 19119.7 & $-4.7 \%$ & 19312.5 & $-5.5 \%$ \\
\hline
\end{tabular}

Note: Absolute values of heating energy consumption are too small and excluded from the percentage variation discussion.

Our first observation from Tables 1-4 is the variation percentages are all negative. It indicates that PCM building envelopes lead to energy conservation in all three studied categories (space heating consumption, space cooling consumption, and total HVAC energy consumption) and all three simulation types ("PCM_OuterLayer", "PCM_MidLayer" and "PCM_InnerLayer") under a dense urban IBE environment despite different heating-cooling load patterns of the four studied cities. The reference building in Los Angeles, CA showed the greatest improvement in heating consumption (-13.7\%), cooling consumption $(-18.3 \%)$, and total energy consumption $(-17.0 \%)$, but had the least energy variations in Minneapolis, MN and Miami, FL which represent the extreme climatological conditions. We also noticed that there is a clear trend and indication in each table that inner PCM layers resulted in more effective thermal storage capability as greater energy reductions occurred. Taking Los Angeles, CA again as an example, the reference building would achieve 17.0 percent of energy conversation when the PCM layer 
is embedded to the indoor side of the building envelope, but could only improve by as little as 6.3 percent when embedding PCMs near the outer layers.

The effectiveness of latent thermal store capability are very dependent on the PCM types, indoor thermostat and local weather condition. We are interested in exploring the influences and proper selections of different PCMs in the inter-building settings. In addition to PCM type "P21", the annual simulation was carried out using five BioPCM materials with different melting temperature range, indicated as "PCM_Q21", "PCM_Q23", "PCM_Q25", "PCM_Q27”, and "PCM_Q29”, respectively. The simulation results of six different types of PCMs embedded in the inner layer of a building envelope across four different weather inputs are reported in Tables 5-8.

Table 5

Reference building's energy consumption with different PCM materials in Washington, D.C.

\begin{tabular}{|c|c|c|c|c|c|c|}
\hline \multirow{2}{*}{$\begin{array}{l}\text { Simulation Type } \\
\text { NoPCM }\end{array}$} & \multicolumn{2}{|c|}{ Heating $(\mathrm{kWh})$} & \multicolumn{2}{|c|}{ Cooling (kWh) } & \multicolumn{2}{|c|}{ Total (kWh) } \\
\hline & 18362.9 & & 7782.9 & & 26145.9 & \\
\hline PCM_P22 & 17596.3 & $-4.2 \%$ & 6716.2 & $-13.7 \%$ & 24312.5 & $-7.0 \%$ \\
\hline PCM_Q21 & 17848.8 & $-2.8 \%$ & 6964.2 & $-10.5 \%$ & 24813.0 & $-5.1 \%$ \\
\hline PCM_Q23 & 17921.9 & $-2.4 \%$ & 6977.8 & $-10.3 \%$ & 24899.7 & $-4.8 \%$ \\
\hline PCM_Q25 & 18147.5 & $-1.2 \%$ & 7253.6 & $-6.8 \%$ & 25401.1 & $-2.8 \%$ \\
\hline PCM_Q27 & 18172.4 & $-1.0 \%$ & 7470.5 & $-4.0 \%$ & 25642.9 & $-1.9 \%$ \\
\hline PCM_Q29 & 18152.5 & $-1.1 \%$ & 7389.0 & $-5.1 \%$ & 25541.4 & $-2.3 \%$ \\
\hline
\end{tabular}

Table 6

Reference building's energy consumption with different PCM materials in Minneapolis, MN

\begin{tabular}{|c|c|c|c|c|c|c|}
\hline Simulation Type & \multicolumn{2}{|c|}{ Heating $(\mathrm{kWh})$} & \multicolumn{2}{|c|}{ Cooling (kWh) } & \multicolumn{2}{|c|}{ Total (kWh) } \\
\hline NoPCM & 33959.6 & & 5787.3 & & 39746.9 & \\
\hline PCM_P22 & 33217.1 & $-2.2 \%$ & 4941.1 & $-14.6 \%$ & 38158.3 & $-4.0 \%$ \\
\hline PCM_Q21 & 33412.0 & $-1.6 \%$ & 5117.2 & $-11.6 \%$ & 38529.2 & $-3.1 \%$ \\
\hline PCM_Q23 & 33482.2 & $-1.4 \%$ & 5125.4 & $-11.4 \%$ & 38607.6 & $-2.9 \%$ \\
\hline PCM_Q25 & 33669.1 & $-0.9 \%$ & 5365.4 & $-7.3 \%$ & 39034.5 & $-1.8 \%$ \\
\hline PCM_Q27 & 33690.3 & $-0.8 \%$ & 5553.0 & $-4.0 \%$ & 39243.4 & $-1.3 \%$ \\
\hline PCM_Q29 & 33674.4 & $-0.8 \%$ & 5483.0 & $-5.3 \%$ & 39157.4 & $-1.5 \%$ \\
\hline
\end{tabular}

Table 7

Reference building's energy consumption with different PCM materials in Los Angeles, CA

\begin{tabular}{|c|c|c|c|c|c|c|}
\hline Simulation Type & $\mathrm{He}$ & Wh) & $\mathrm{Cos}$ & Nh) & \multicolumn{2}{|c|}{ Total (kWh) } \\
\hline NoPCM & 3078.9 & & 7321.5 & & 10400.4 & \\
\hline PCM_P22 & 2655.9 & $-13.7 \%$ & 5978.6 & $-18.3 \%$ & 8634.5 & $-17.0 \%$ \\
\hline PCM_Q21 & 2676.7 & $-13.1 \%$ & 6100.5 & $-16.7 \%$ & 8777.2 & $-15.6 \%$ \\
\hline PCM_Q23 & 2743.4 & $-10.9 \%$ & 6083.2 & $-16.9 \%$ & 8826.6 & $-15.1 \%$ \\
\hline PCM Q25 & 2987.0 & $-3.0 \%$ & 6654.5 & $-9.1 \%$ & 9641.4 & $-7.3 \%$ \\
\hline
\end{tabular}




\begin{tabular}{lllllrl} 
PCM_Q27 & 3016.4 & $-2.0 \%$ & 6990.8 & $-4.5 \%$ & 10007.3 & $-3.8 \%$ \\
PCM_Q29 & 2988.0 & $-3.0 \%$ & 6843.7 & $-6.5 \%$ & 9831.7 & $-5.5 \%$ \\
\hline
\end{tabular}

Table 8

Reference building's energy consumption with different PCM materials in Miami, FL

\begin{tabular}{|c|c|c|c|c|c|c|}
\hline Simulation Type & \multicolumn{2}{|c|}{ Heating (kWh) } & \multicolumn{2}{|c|}{ Cooling (kWh) } & \multicolumn{2}{|c|}{ Total (kWh) } \\
\hline NoPCM & 377.0 & & 20062.6 & & 20439.6 & \\
\hline PCM_P22 & 192.7 & $-48.9 \%$ & 19119.7 & $-4.7 \%$ & 19312.5 & $-5.5 \%$ \\
\hline PCM_Q21 & 198.8 & $-47.3 \%$ & 19516.9 & $-2.7 \%$ & 19715.7 & $-3.5 \%$ \\
\hline PCM_Q23 & 226.4 & $-39.9 \%$ & 19402.0 & $-3.3 \%$ & 19628.4 & $-4.0 \%$ \\
\hline PCM_Q25 & 340.9 & $-9.6 \%$ & 19334.7 & $-3.6 \%$ & 19675.6 & $-3.7 \%$ \\
\hline PCM_Q27 & 357.0 & $-5.3 \%$ & 19578.7 & $-2.4 \%$ & 19935.7 & $-2.5 \%$ \\
\hline PCM_Q29 & 348.6 & $-7.5 \%$ & 19488.1 & $-2.9 \%$ & 19836.7 & $-2.9 \%$ \\
\hline
\end{tabular}

The reductions of the reference building's total energy consumption are also plotted in Figure 2. The Tables 5-8 indicate that different selection of PCM layers lead to varying building thermal-energy performance, and the reference building in our inter-building settings achieves the best performance with type "PCM_P22". Among all BioPCMs, "PCM_Q21" and "PCM_Q22” demonstrate significantly better performance compared to the other three in Washington, D.C., Minneapolis, MN, Los Angeles, CA. However in Miami, FL, selections of PCMs did not result in much difference due to its long hot summer and short warm winter.

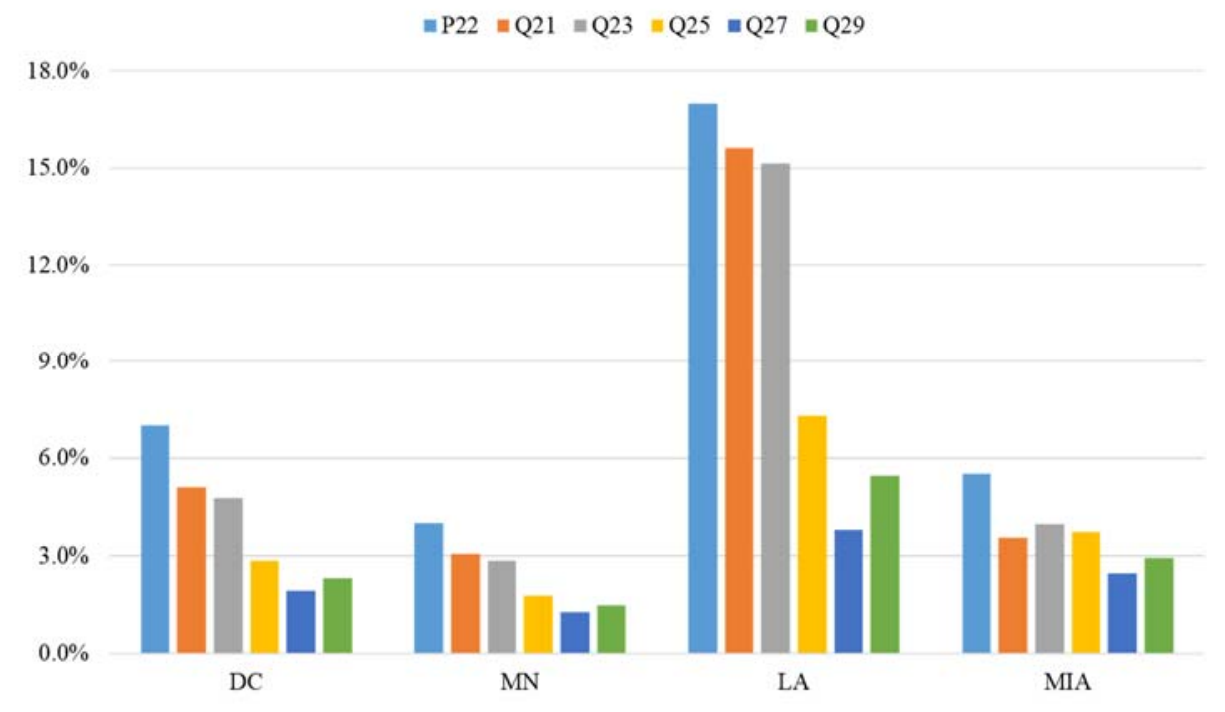

Fig. 3. Reductions of reference building's total energy consumption by six different PCM types 


\subsection{Case Study 2: The impact of location of PCMs of building envelopes on inter- building thermal-energy performance}

In order to understand the influences and energy implications by PCM roofs and PCM walls separately within an inter-building environment, we then designed and simulated how the reference building's energy performance would change due to the PCM locations in the building envelopes in Case Study 2. The results of the reference buildings' space heating, space cooling, and total primary energy are reported in the Tables 9-12 for our cross-regional analysis. Similarly, "NoPCM" stands for the baseline value as no PCM technology is implemented in the building network models. "PCM_RoofOnly" and "PCM_WallOnly" indicate the cases that PCMs are only applied to roof areas and exterior wall areas, respectively, and the "PCM_Entire" denotes the case that PCM layers covered the entire building envelopes. For all analyses of this case study, PCM type and the location of PCM layers within the envelope volume are set as control parameters. PCM type "P22" is used and the PCM layers are embedded as inner layers toward the most effective situation. The interpretation of symbols ("+" and "-") stay the same as previous case.

Table 9

Reference building's energy consumption with different PCM layer locations in Washington, D.C.

\begin{tabular}{|c|c|c|c|c|c|c|}
\hline Simulation Type & \multicolumn{2}{|c|}{ Heating $(\mathrm{kWh})$} & \multicolumn{2}{|c|}{ Cooling (kWh) } & \multicolumn{2}{|c|}{ Total $(\mathrm{kWh})$} \\
\hline NoPCM & 18362.9 & & 7782.9 & & 26145.9 & \\
\hline PCM_RoofOnly & 17924.2 & $-2.4 \%$ & 7012.9 & $-9.9 \%$ & 24937.2 & $-4.6 \%$ \\
\hline PCM_WallOnly & 17815.5 & $-3.0 \%$ & 7155.3 & $-8.1 \%$ & 24970.8 & $-4.5 \%$ \\
\hline PCM_Entire & 17596.3 & $-4.2 \%$ & 6716.2 & $-13.7 \%$ & 24312.5 & $-7.0 \%$ \\
\hline
\end{tabular}

Table 10

Reference building's energy consumption with different PCM layer locations in Minneapolis, MN

\begin{tabular}{|c|c|c|c|c|c|c|}
\hline Simulation Type & \multicolumn{2}{|c|}{ Heating (kWh) } & \multicolumn{2}{|c|}{ Cooling (kWh) } & \multicolumn{2}{|c|}{ Total $(\mathrm{kWh})$} \\
\hline NoPCM & 33959.6 & & 5787.3 & & 39746.9 & \\
\hline PCM_RoofOnly & 33597.2 & $-1.1 \%$ & 5186.5 & $-10.4 \%$ & 38783.6 & $-2.4 \%$ \\
\hline PCM_WallOnly & 33416.6 & $-1.6 \%$ & 5261.7 & $-9.1 \%$ & 38678.3 & $-2.7 \%$ \\
\hline PCM_Entire & 33217.1 & $-2.2 \%$ & 4941.1 & $-14.6 \%$ & 38158.3 & $-4.0 \%$ \\
\hline
\end{tabular}

Table 11

Reference building's energy consumption with different PCM layer locations in Los Angeles, CA

\begin{tabular}{llll}
\hline Simulation Type & Heating $(\mathrm{kWh})$ & Cooling $(\mathrm{kWh})$ & Total $(\mathrm{kWh})$ \\
\hline NoPCM & 3078.9 & 7321.5 & 10400.4
\end{tabular}




\begin{tabular}{lllllll} 
PCM_RoofOnly & 2802.8 & $-9.0 \%$ & 6348.0 & $-13.3 \%$ & 9150.8 & $-12.0 \%$ \\
PCM_WallOnly & 2715.7 & $-11.8 \%$ & 6463.3 & $-11.7 \%$ & 9179.0 & $-11.7 \%$ \\
PCM_Entire & 2655.9 & $-13.7 \%$ & 5978.6 & $-18.3 \%$ & 8634.5 & $-17.0 \%$ \\
\hline
\end{tabular}

Table 12

Reference building's energy consumption with different PCM layer locations in Miami, FL

\begin{tabular}{|c|c|c|c|c|c|c|}
\hline Simulation Type & \multicolumn{2}{|c|}{ Heating (kWh) } & \multicolumn{2}{|c|}{ Cooling (kWh) } & \multicolumn{2}{|c|}{ Total $(\mathrm{kWh})$} \\
\hline NoPCM & 377.0 & & 20062.6 & & 20439.6 & \\
\hline PCM_RoofOnly & 281.3 & $-25.4 \%$ & 19379.4 & $-3.4 \%$ & 19660.7 & $-3.8 \%$ \\
\hline PCM_WallOnly & 195.8 & $-48.0 \%$ & 19471.0 & $-2.9 \%$ & 19666.8 & $-3.8 \%$ \\
\hline PCM_Entire & 192.7 & $-48.9 \%$ & 19119.7 & $-4.7 \%$ & 19312.5 & $-5.5 \%$ \\
\hline
\end{tabular}

The numbers in Tables 9-12 are consistent with our previous results and further support that Los Angeles, CA and Washington, D.C. benefit the most from PCM-embedded building layers. Here again we observe that every simulated case leads to a reduction in energy consumptions. It is interesting to note that PCM roofs and PCM vertical walls bring similar energy improvement of the reference buildings. The variation percentages of total energy consumption of "PCM_RoofOnly" and "PCM_WallOnly" are almost identical in the simulated four cities ("-4.6\%" and "-4.5\%" in Washington, D.C., "-2.4\%" and "2.7\%" in Minneapolis, MN, “-12\%" and "-11.7\%" in Los Angeles, CA, “-4.6\%" and “-4.5\%" in Miami, FL). However, a combination of PCM-embedded roofs and PCM-embedded walls could result in about 50 percent more energy reduction. This could be due to a more stable indoor thermal performance of an enclosed area. In the inter-building urban settings, the PCM roof could be favorable to deal with direct sunlight and solar radiation, while PCM vertical building envelopes could be more effective with offsetting the thermal-energy perturbation by mutual shading and mutual reflection of spatial proximal buildings.

\section{Discussion}

Due to economic booms, urban sprawl and population migration, buildings and the urban built environment have contributed significantly to and will continue to exacerbate global energy and environmental concerns. A great deal of research effort has focused on reducing building energy 
consumption and achieving a more sustainable built environment $[30,31]$. To treat buildings as standalone entities would ignore the neighboring buildings within their building networks that may substantially perturb the thermal-energy performance and the local micro-climate. Recent research [14, 15] has demonstrated that one building's energy performance and supply prediction can be greatly influenced by its nearby microenvironment creating Inter-Building Effects (IBE) within spatially-proximal building networks. In order to understand the complex IBE and further seek solutions to mitigate the negative impact within urban building network, researchers have studied the mutual shading and mutual reflection through a nuanced disaggregate analysis [17]. Although the research found shading to contribute to increased heating and lighting loads while reflection increased cooling energy required for spatiallyproximal buildings, the contribution of reflection and shading varied on a month-to-month basis. Tropical cities with longer summers, longer daylight time and more demand for cooling energy would benefit when reflection effect is mitigated all year around. Directional reflective building envelopes have been shown to mitigation UHI effects and improve energy consumption by lessening the mutual reflection within urban building canopies, especially for tropical cites $[16,32]$. However, we still lack strategies to promote sustainable and energy-responsive buildings in the context of a dense building network. The research presented in this paper contributes to the exploration of solutions to mitigate the negative impact by the IBE in dense urban settings.

With the capabilities to shift and decrease peak loads, PCMs have been considered as promising building application to both improve human indoor living comfort and reduce building energy consumption without a substantial increase in the weight of the construction material. Previous empirical and numerical studies demonstrate that PCMs have different benefits depending on quantity and types of PCM selection, locations of implementation and climates, but mostly discussed from the perspective of stand-alone buildings $[19,21,27,29]$. This paper contributes a systematic approach to examine and expand the use of PCM technology from a single building analysis to a more realistic inter-building environment. To test our Hypotheses 1 and 1a, we first introduced a systematic approach to test the reference building's energy performance while the PCMs are embedded in the inner layer, middle layer, 
and outer layer of the volume of the building envelopes, respectively. We found the application of PCM embedded building envelopes to contribute to decreasing loads in both heating and cooling despite the four different and distinct climatic conditions. The total primary energy consumption for HVAC was reduced by up to $17 \%$. This is due to the fact that PCMs raise the building inertia to solar light which initiates mutual shading and mutual reflection of IBE, and may help to minimize negative mutual influences between buildings that lead to increases in energy consumption in urban environments. Consistent with a previous empirical study [24], we found better performance for inner layers in all four tested cites. This is due to the fact that the PCM was in the partially-melted state before cooling and was able to release latent heat during cooling processes, which results in the best performance of PCM envelopes [23]. Thus we found support for our Hypotheses 1 and 1a. The intensity of IBE and the performance of PCM have been discussed in previous research to be highly dependent on the local climatological conditions. In our analysis, one temperate city, Washington, D.C. and one subtropical city, Los Angeles, CA, were shown to be more effective when PCM-embedded layers are applied to the interbuilding context owing to larger temperature variation over the course of each simulation day and larger temperature fluctuation over the course of the simulation year comparing to extreme conditions. Thus, our research supports the finding that IBE results and PCM impact are dependent on local conditions.

The roof area of a building is exposed to sun over the course of daylight hours and absorbs more solar radiation compared to the other areas of a building, and thus has become a critical area for building applications to improve energy consumption. For instance, green roofs $[33,34]$ and cool roofs $[35,36]$ have been widely studied to mitigate UHI effects. Previous PCM research also suggest the placement of PCMs layers on roofs to be more efficient in single building cases [19]. To expand our understanding of PCM application in the inter-building scenario, we tested the impact of a PCM-embedded roof scenario, a PCM-embedded wall scenario, and a combined PCM-embedded envelope (wall and roof) scenario, respectively for a comparative analysis. The results revealed that vertical building envelopes and roofs are equally important in improving the reference building's thermal energy performance. However, embedding PCM in both the roof and the wall over the entire building envelope would improve 50 
percent more depending on the simulated city. It accomplishes this by creating a more thermally stable enclosed indoor area. This outcome is found consistently in all the four simulated urban cities. Thus, we found support for our Hypothesis 2 as PCM-embedded building walls and roofs have positive influences on energy saving.

To examine the sensitivity of these findings based on the type of PCM material utilized, we tested six types of PCMs with different melting ranges and temperature-enthalpy profiles in our simulated interbuilding urban setting. We found that the reference building's energy performance varies when different PCMs were used. However, in all PCM types simulated and for all four climatological contexts we found PCMs to result in reductions in energy consumption. This suggests that the introduction of PCMs is an effective strategy for reducing energy consumption of buildings in urban settings but that the appropriate selection of PCM type used to achieve better thermal performance depends on the local weather conditions.

Motivated to explore strategies to reduce the negative energy and environmental implications of inter-building effects in cities, this research was initiated to examine and quantify the impact of PCMembedded building envelopes on thermal-energy dynamics within an inter-building environment. It provided us with a more explicit understanding of the dynamic response of PCM technology to interbuilding relationships. The simulation results demonstrate that PCM-embedded building envelopes could serve as possible solutions to mitigate unfavorable thermal-energy IBE outcomes, and the parametric analysis also suggests more effective practices to take advantage of the latent heat capacity in a more realistic inter-building environment. A human-based check was conducted to ensure the accuracy of the dynamic simulation input and output in executing the dynamic simulation. No exceptional results, warming, or error messages were observed over the course of the simulation. Nevertheless, the modeling and simulation efforts also result in several limitations. The hypothetical building network model we inherited for this study contains only nine buildings with identical morphology. The purpose of such urban settings is to not only to keep the research scope reasonable, but also sufficient enough to examine our hypotheses and research questions. It is possible that a more complicated outcome due to larger urban 
scale may exist and, if so, was neglected in the research. Future research should address the limitations to understand the impact of PCMs from a larger scale analysis, incorporate empirical studies using thermal sensing technology that could calibrate simulation analysis, as well as seek out other measures that could be used to mitigate the negative IBE impacts.

\section{Conclusions}

We investigated the potential of PCM technology within an inter-building micro-environment to reduce the negative impact on energy use that can result in spatially proximal building networks. We developed and demonstrated a systematic approach to examine the impact of PCM embedded building envelopes in an inter-building context. This research built upon and extended previous IBE modeling approaches that studied energy predictions in a dense urban building network. A hypothetic building network was modeled in the dynamic EnergyPlus simulation environment under the climatological contexts of four typical cities in the United States. The energy consumption of the reference building demonstrated considerable improvement and consistent reductions across our simulated contexts, although the magnitude of reductions was dependent on local climatological conditions. The placement location of PCM-embedded layers was found to be especially important in order to make full use of the thermal storage capacity of PCMs. We also studied and discussed better practices for more effective PCM application in the inter-building environment through parametric analysis. This research expands our understanding of the use of PCMs from a stand-alone building scenario to an urban dense inter-building environment. The results suggest PCM building envelopes as possible solutions to mitigate negative interbuilding influences and improve energy efficiency within urban building networks, especially in temperate cities. Urbanization is exacerbating energy and environmental challenges created by the tighter spatial building interrelationships in cities. Therefore, future research is critically needed to develop strategies-like the PCM embedded envelop strategies presented in this paper-to reduce the intensity of Inter-Building Effects and achieve comfortable, energy efficient and sustainable cities. 


\section{Acknowledgements}

This material is based in part upon work supported by the National Science Foundation under Grant No. 1142379 and by the BioBuild Virginia Tech Interdisciplinary Graduate Education Program grant. Any opinions, findings, and conclusions or recommendations expressed in this material are those of the authors and do not necessarily reflect the views of the National Science Foundation or the BioBuild Interdisciplinary Graduate Education Program.

\section{References}

[1] International Energy Agency, Key World Energy Statistic, in, International Energy Agency, 2013.

[2] M.J. Alcoforado, H. Andrade, Global warming and the urban heat island, in: Urban ecology, Springer, 2008, pp. 249-262.

[3] P.A. Smithson, IPCC, 2001: climate change 2001: the scientific basis, Contribution of Working Group, 1 (2002) 1144-1144.

[4] A.M. Rizwan, L.Y. Dennis, C. Liu, A review on the generation, determination and mitigation of Urban Heat Island, Journal of Environmental Sciences, 20 (1) (2008) 120-128.

[5] K. Giannopoulou, I. Livada, M. Santamouris, M. Saliari, M. Assimakopoulos, Y.G. Caouris, On the characteristics of the summer urban heat island in Athens, Greece, Sustainable Cities and Society, 1 (1) (2011) 16-28.

[6] M.P. McCarthy, M.J. Best, R.A. Betts, Climate change in cities due to global warming and urban effects, Geophys. Res. Lett., 37 (9) (2010).

[7] International Energy Agency, Energy Efficiency, in, 2013.

[8] U.S. Department of Energy, Building Energy Data Book, in, 2011.

[9] R. Madlener, Y. Sunak, Impacts of urbanization on urban structures and energy demand: What can we learn for urban energy planning and urbanization management?, Sustainable Cities and Society, 1 (1) (2011) 45-53.

[10] UN DESA, World Urbanization Prospects, the 2011 Revision, in, United Nations, 2011.

[11] E. Krüger, D. Pearlmutter, F. Rasia, Evaluating the impact of canyon geometry and orientation on cooling loads in a high-mass building in a hot dry environment, Appl. Energy, 87 (6) (2010) 2068-2078.

[12] F.S. de la Flor, S.A. Domínguez, Modelling microclimate in urban environments and assessing its influence on the performance of surrounding buildings, Energy Build., 36 (5) (2004) 403-413. 
[13] R. Yao, K. Steemers, Urban Microclimates and Simulation, in, Design and Management of Sustainable Built Environments, Springer, 2013, pp. 77-97.

[14] A.L. Pisello, J.E. Taylor, X. Xu, F. Cotana, Inter-building effect: Simulating the impact of a network of buildings on the accuracy of building energy performance predictions, Build. Environ., 58 (0) (2012) $37-45$.

[15] A.L. Pisello, V.L. Castaldo, J.E. Taylor, F. Cotana, Expanding Inter-Building Effect modeling to examine primary energy for lighting, Energy Build., 76 (0) (2014) 513-523.

[16] Y. Han, J.E. Taylor, A.L. Pisello, Toward mitigating urban heat island effects: Investigating the thermal-energy impact of bio-inspired retro-reflective building envelopes in dense urban settings, Energy Build., 102 (2015) 380-389.

[17] Y. Han, J.E. Taylor, A.L. Pisello, Exploring mutual shading and mutual reflection inter-building effects on building energy performance, Appl. Energy.

[18] J.F. Belmonte, P. Eguía, A.E. Molina, J.A. Almendros-Ibáñez, Thermal simulation and system optimization of a chilled ceiling coupled with a floor containing a phase change material (PCM), Sustainable Cities and Society, 14 (2015) 154-170.

[19] D. Zhou, C.Y. Zhao, Y. Tian, Review on thermal energy storage with phase change materials (PCMs) in building applications, Appl. Energy, 92 (2012) 593-605.

[20] Pomianowski, Michal, Per Heiselberg, and Yinping Zhang. "Review of thermal energy storage technologies based on PCM application in buildings." Energy Build. 67 (2013) 56-69.

[21] D.N. Nkwetta, F. Haghighat, Thermal energy storage with phase change material—A state-of-the art review, Sustainable Cities and Society, 10 (2014) 87-100.

[22] R. Baetens, B.P. Jelle, A. Gustavsen, Phase change materials for building applications: A state-ofthe-art review, Energy Build., 42 (9) (2010) 1361-1368.

[23] X. Jin, S. Zhang, X. Xu, X. Zhang, Effects of PCM state on its phase change performance and the thermal performance of building walls, Build. Environ., 81 (2014) 334-339.

[24] X. Jin, M.A. Medina, X. Zhang, On the importance of the location of PCMs in building walls for enhanced thermal performance, Appl. Energy, 106 (2013) 72-78.

[25] L. UIUC, EnergyPlus engineering reference: the reference to EnergyPlus calculations, US Department of Energy, (2005).

[26] D.B. Crawley, L.K. Lawrie, F.C. Winkelmann, W.F. Buhl, Y.J. Huang, C.O. Pedersen, R.K. Strand, R.J. Liesen, D.E. Fisher, M.J. Witte, EnergyPlus: creating a new-generation building energy simulation program, Energy Build., 33 (4) (2001) 319-331.

[27] J.S. Sage-Lauck, D.J. Sailor, Evaluation of phase change materials for improving thermal comfort in a super-insulated residential building, Energy Build., 79 (2014) 32-40. 
[28] M. Alam, H. Jamil, J. Sanjayan, J. Wilson, Energy saving potential of phase change materials in major Australian cities, Energy Build., 78 (2014) 192-201.

[29] P.C. Tabares-Velasco, C. Christensen, M. Bianchi, Verification and validation of EnergyPlus phase change material model for opaque wall assemblies, Build. Environ., 54 (2012) 186-196.

[30] U. Berardi, Clarifying the new interpretations of the concept of sustainable building, Sustainable Cities and Society, 8 (2013) 72-78.

[31] K. Parrish, R. Singh, S.-C. Chien, The role of international institutional partnerships in delivering low-energy building design: A case study, Sustainable Cities and Society, 14 (2015) 383-389.

[32] F. Rossi, A.L. Pisello, A. Nicolini, M. Filipponi, M. Palombo, Analysis of retro-reflective surfaces for urban heat island mitigation: A new analytical model, Appl. Energy, 114 (2014) 621-631.

[33] J. Goussous, H. Siam, H. Alzoubi, Prospects of green roof technology for energy and thermal benefits in buildings: Case of Jordan, Sustainable Cities and Society, 14 (2015) 425-440.

[34] A. Niachou, K. Papakonstantinou, M. Santamouris, A. Tsangrassoulis, G. Mihalakakou, Analysis of the green roof thermal properties and investigation of its energy performance, Energy Build., 33 (7) (2001) 719-729.

[35] A.L. Pisello, F. Cotana, The thermal effect of an innovative cool roof on residential buildings in Italy: Results from two years of continuous monitoring, Energy Build., 69 (2014) 154-164.

[36] C. Romeo, M. Zinzi, Impact of a cool roof application on the energy and comfort performance in an existing non-residential building. A Sicilian case study, Energy Build., 67 (2013) 647-657. 